\title{
O que determina a ocorrência e/ou o registro de um crime em Minas Gerais?
}

\author{
Ludmila Mendonça Lopes Ribeiro \\ Doutora em Sociologia pelo Instituto Universitário de Pesquisas do Rio de Janeiro \\ Professora no Departamento de Sociologia da Universidade Federal de Minas Gerais \\ ludmila.ribeiro@gmail.com \\ Luiza Meira Bastos \\ Mestre em Sociologia pela Universidade Federal de Minas Gerais \\ bastosm.luiza@gmail.com
}

\begin{abstract}
Resumo A proposta deste artigo é compreender em que medida as taxas de crimes e seus registros são afetados pela disponibilidade de recursos e serviços de segurança pública e justiça criminal. Como contraponto empírico foi utilizado o Índice Mineiro de Responsabilidade Social (IMRS), que reúne, no nível municipal, dados agregados sobre saúde; educação; habitação e meio ambiente; segurança pública; renda e emprego; gestão fiscal; cultura; desporto e lazer. Foram consultados os dados relativos a um período de dez anos (2004-2014) para a temática da segurança pública. Com base na modelagem estatística dos dados disponíveis, constatou-se que, quanto maior a disponibilidade de recursos humanos e institucionais de segurança pública e justiça criminal, maior a concentração de registros de criminalidade e do crime propriamente dito, ao contrário do que pressupõe a literatura criminológica internacional.
\end{abstract}

Palavras-chave: Teoria criminológica, IMRS, crimes violentos, homicídios dolosos.

\section{Introdução}

Teste artigo procuramos entender de que maneira as taxas de cri1 mes e seus registros são afetados pela disponibilidade de recursos e serviços de segurança pública e justiça criminal. Para tanto, será utilizada a teoria da dissuasão, uma formulação teórica segundo a qual a elevada concentração de agentes e agências policiais, judiciais e prisionais em uma cidade faz com que ela se torne imune a elevadas taxas de criminalidade.

A base de dados escolhida para o teste desta hipótese foi a do Índice Mineiro de Responsabilidade Social (IMRS), que reúne uma série de informações sociais, econômicas, criminais e institucionais para todos os municípios do estado de Minas Gerais. O IMRS é resultado da Lei $n^{\circ}$ 15.011, de 2004, que estabeleceu a responsabilidade da Fundação João Pinheiro de construir esse índice, a ser calculado com base em informações disponibilizadas pelo IBGE, pelas instituições que trabalham em âmbito municipal e, ainda, por pesquisas realizadas periodicamente por organizações governamentais. A lei prevê que sejam consideradas, na elaboração do IMRS, oito esferas da vida social (saúde; educação; habitação e meio ambiente; segurança pública; renda e emprego; gestão fiscal; cultura; desporto e lazer) e que os dados sejam disponibilizados de forma livre a cada dois anos. ${ }^{1}$ 
Para organizar o teste da teoria da dissuasão sob uma perspectiva integrada, dividimos este artigo em cinco seções, além desta introdução. $\mathrm{Na}$ primeira, construímos o arcabouço teórico que será mobilizado para a análise do IMRS. Na segunda, apontamos as variáveis selecionadas para teste da teoria. Na terceira, descrevemos os modelos estatísticos que melhor explicam a variação da criminalidade no tempo e no espaço. Na quarta, problematizamos de que maneira os dados analisados reforçam ou rechaçam a teoria da dissuasão. Por fim, apresentamos algumas considerações finais discutindo a forma pela qual o crime pode ser um indicador da vulnerabilidade institucional dos municípios mineiros.

\section{O que explica a ocorrência do crime na presença da polícia e das instituições de justiça?}

A compreensão de como o crime violento se distribui na cidade, estado ou país é tema tradicional de vários estudos na área de ciências sociais. Porém, no caso brasileiro, poucos são os trabalhos destinados à construção de uma teoria sobre os determinantes da criminalidade, ou ainda, à realização de teste de abordagens há muito conhecidas em outros contextos.

Se a sociologia do crime no Brasil tem se despertado para compreender, sob uma perspectiva mais empírica, quais são e como são operados os desdobramentos institucionais de um fenômeno categorizado como crime (Freitas; Ribeiro, 2014), ${ }^{2}$ a proposta deste artigo é enfatizar as causas da criminalidade com base na teoria da dissuasão, que parte do pressuposto de que o maior determinante do crime é a incerteza da punição. Dentro desse constructo, as ações humanas são baseadas em decisões racionais alicerçadas no cálculo acerca das prováveis consequências de cada uma dessas ações. Assim, "o delito ocorre quando o cálculo racional da dor da punição legal compensa a motivação para o crime" (Akers, 1990, p. 654).

A formulação original dessa teoria data do século XVIII, sendo conhecida como criminologia clássica, e tem como principais expoentes indivíduos que procuravam, com seus estudos, tornar o sistema de justiça criminal mais eficiente e mais humano. Jeremy Bentham, reformador inglês, acreditava que as punições não eram capazes de dissuadir o indivíduo da prática de um delito porque eram excepcionais. Tal incapacidade prevalecia ainda que as punições fossem extremamente desumanas, como a humilhação do criminoso em praça pública ou a violência física e moral contra o condenado nas masmorras onde permanecia à espera de julgamento (Bentham, 2002).

As ideias de Bentham tiveram desdobramentos diretos para a campanha de Beccaria contra a pena de morte, em 1760, para a reforma dos códigos limitando os poderes dos "déspotas esclarecidos" e para os decretos revolucionários franceses contra a pena capital. Todo esse movimento culminou na restrição da pena de morte para assassinato em primeiro grau e traição, na Inglaterra, bem como na mudança da finalidade da prisão, que, de lugar para a espera do julgamento, passou a lugar para a reforma dos indivíduos (Ignatieff, 1981).

Todavia, o novo sistema de punição não significou taxas menores de homicídios intencionais e de crimes em geral. Na visão de Beccaria, a humanização das penas não reduziria a quantidade de crimes, porque o sistema de justiça criminal era extremamente seletivo; sendo assim, de nada adiantava mudar a forma de punição se as estratégias de apuração da responsabilidade do indivíduo no cometimento de delitos continuavam seletivas, desumanas e ineficazes. Como argumenta Ignatieff (1981, p. 167), inúmeras ilegalidades eram toleradas por causa da fraqueza persistente do Estado, pois a polícia e o Judiciário tornavam-se agências encarregadas da resolução de disputas privadas, com uma seletividade muito acentuada e um constante favorecimento dos nobres em detrimento dos pobres. Este era o motivo da permanência das taxas de criminalidade em patamares elevados. Para Beccaria, a contenção dos delitos, em geral, apenas ocorreria se a certeza da punição se tornasse igualitária, ou seja, se a punição estivesse disponível para todos os indivíduos. Este requisito era mais importante para o funcionamento das agências públicas do que a severidade da punição. Era preciso, portanto, reformar polícia e justiça, de forma a mitigar sua seletividade.

Na virada do século XVIII para o XIX, a polícia era uma espécie de milícia, isto é, uma série de indivíduos contratados, muitas vezes, pelos reis e nobres, para a manutenção da ordem e a proteção da propriedade privada. Não havia qualquer critério de seleção e treinamento desses sujeitos, sendo que o ingresso do indivíduo na carreira policial se dava meramente com o pagamento de seus salários e a concessão a ele de alguma arma ou instrumento cortante que viabilizasse a proteção dos bens e da própria pessoa que contratava essa força. A profissionalização da polícia, como agência encarregada da manutenção da ordem e detecção

1. Atualmente, os dados do Índice Mineiro de Responsabilidade Social estão disponíveis em: <http://imrs.fjp.mg.gov.br/Home/IMRS> .

2. Nesse ponto, são incluídas como desdobramentos institucionais tanto a administração do fenômeno chamado crime pelas agências do sistema de justiça criminal quanto as políticas de prevenção das ações criminais. 
de desvios, tem como pedra angular a edição do Bill for improving the Police in and near the Metropolis, editado por Robert Peel em 1829 (Skolnick, 1966, p. 2).

É a partir dessa legislação que o mandato policial se torna claro no tocante a dois aspectos: o não uso da violência para a contenção da criminalidade e, ainda, a restrição aos dispositivos constitucionais da garantia da segurança a todos os indivíduos residentes nas cidades. É nesse momento que se propõe a ideia de que as forças policiais devem ser constrangidas pelo princípio do rule of law, isto é, todas as suas ações devem estar sujeitas a revisão por outros poderes republicanos. Esse princípio mantém a instituição policial e seus profissionais accountables, retirando de sua atuação qualquer tipo de viés político (Skolnick; Bayley, 2006). Em suma, acima da polícia estão os direitos de liberdade e igualdade dos cidadãos, materializados na Constituição. Para garantir a correta aplicação desses direitos, existe o Poder Judiciário.

A reforma do sistema judicial também data da passagem do século XVIII para o XIX. É nesse período que as funções de acusação são separadas das funções de julgamento, e ambas passam a ser exercidas por promotores e juízes, respectivamente (Foucault, 2001). Como forma de garantia da especialização dessas instituições, reforça-se que "a competência social e técnica para dizer o direito é uma condição ou um requisito de entrada no campo jurídico, por meio do título de licenciado em Direito, ou do reconhecimento oficial para exercer determinada profissão jurídica" (Azevedo, 2011, p. 39). Os tribunais superiores passam, então, a zelar pela garantia da aplicação uniforme e equânime da lei em detrimento da satisfação de interesses privados.

A consolidação dessas mudanças ocorre na virada do século XIX para o século XX, quando se dá a institucionalização de um sistema de segurança pública e justiça criminal profissional, isto é, um sistema preparado para a prevenção e repressão do delito, de maneira imparcial e suficientemente rápida, tornando mais provável a certeza da punição. Seu funcionamento mostraria a qualquer indivíduo o quanto a sociedade é intolerante ao cometimento de crimes, dispondo, por isso, de um aparato de controle pronto para engendrar punições. É nesse momento que as formulações iniciais de Bentham e de Beccaria ganham corpo e se constituem na teoria da dissuasão, que entende $o$ comportamento criminoso como sendo decorrente de um cálculo racional em que o indivíduo avalia se o sistema de justiça criminal é eficiente o bastante para de- tectar e processar esse tipo de comportamento. Caso a resposta seja negativa, as motivações para o crime já se encontram como dadas.

Nessa mesma direção, Achen e Snidal (1989, p. 149) argumentam que a teoria da dissuasão tem um componente eminentemente psicológico, entendendo o comportamento do indivíduo como decorrente de uma espécie de escolha racional. Como em um modelo estatístico, o sujeito soma os benefícios e subtrai as possíveis implicações de sua conduta. Caso o resultado seja positivo, a ação criminosa será praticada. Ocorre que nem sempre as informações de que o indivíduo dispõe permitem um bom ajuste do modelo, o que irá gerar estimativas enviesadas sobre a possibilidade de sua identificação e punição como criminoso, o que pode levar a mais ou menos comportamentos desviantes. Mais do que a real probabilidade de punição, importa a percepção que os indivíduos têm da chance de detecção e detenção no caso da prática de crimes.

Por essa razão, mudanças na constituição e no funcionamento do sistema de segurança pública e justiça criminal podem ter impacto muito direto na maneira como os indivíduos se comportam em sociedade. Para Norbert Elias (1993), por exemplo, é a partir do momento em que o sistema de justiça se torna mais eficiente na garantia de seu monopólio da força física que se acelera a constrição dos impulsos egoístas individuais. Com isso, diminuem-se as soluções privadas de conflitos públicos e, dessa forma, os homicídios intencionais. Em consequência, o indivíduo é protegido contra ataques súbitos e, simultaneamente, forçado a reprimir em si mesmo qualquer impulso emocional para atacar outra pessoa (Elias, 1993, p. 198).

Se no século XX a reforma do sistema de segurança pública, justiça criminal e prisões já era bem-sucedida na Europa, ela ainda engatinhava nas Américas. Mesmo nos Estados Unidos da América, a incidência de crimes era bastante elevada nas primeiras décadas daquele século. Ao final dos anos 1960, Gary Becker realizou uma análise estritamente econômica dos determinantes do crime, denominando-a teoria da escolha racional, que em muito se assemelha à teoria da dissuasão, sendo várias vezes entendida como outra face da mesma moeda. ${ }^{3}$ De acordo com este modelo, os criminosos calculam os custos e benefícios das atividades criminosas. Os benefícios são as receitas esperadas dessa espécie de atividade, ou seja, os produtos do crime. Os custos são representados por custos monetários do crime (perda de rendimentos

3. Tal como destacado por Akers (1990, p. 654), apesar da conexão principiológica entre as duas teorias, "a escolha racional não entrou na criminologia principalmente como pesquisa ou teoria da dissuasão; em vez disso, foi introduzida pela primeira vez através de análises econômicas do crime. Anos mais tarde, criminologistas envolvidos na investigação sobre a dissuasão utilizaram o modelo econômico da escolha racional para modificar ou expandir a dissuasão [no que se referia a] determinantes do crime. A ligação entre a teoria da dissuasão e da escolha racional, desde então, torna-se bem estabelecida na literatura". 
em atividades alternativas) e pela sentença esperada (probabilidade de ser apanhado, processado e julgado com uma condenação).

Na perspectiva de Gary Becker (1968, p. 2), a obediência à lei não pode ser entendida como algo natural, o que era evidente na quantidade de recursos que se investiam ao final da década de 1960 no reforço aos preceitos legais (que incluíam desde a contratação de novos policiais até as campanhas educativas), na prevenção de crimes e na captura de criminosos. Isso significa dizer que a simples existência de uma probabilidade de punição abstrata não é suficiente para dissuadir o indivíduo da prática de um delito, devendo essa possibilidade ser enfatizada através do padrão de operação das agências de controle e, ainda, da magnitude ou da severidade da sanção.

Para a teoria da escolha racional, quanto menor é a expectativa de uma condenação, maior é a probabilidade de o indivíduo cometer um crime, qualquer que seja ele. Por isso, uma forma de reduzir a probabilidade de incidência do delito é aumentar os agentes e as agências do sistema de segurança pública e justiça criminal: quanto maior a quantidade de policiais, maior a detecção de crimes e criminosos; quanto maior a quantidade de promotores de justiça, maior a probabilidade de que o indivíduo apontado como suspeito pela polícia seja acusado na Justiça; quanto maior a quantidade de juízes, maior a probabilidade de que o crime seja processado rapidamente; quanto maior a quantidade de vagas nas prisões, maior a quantidade de indivíduos condenados. Em resumo, uma forma de construir cidades seguras com base nesta perspectiva é aumentar a capacidade das instituições responsáveis pela repressão do crime.

A despeito de reconhecer que essa abordagem não contempla as diferentes esferas não racionais que interferem na determinação do curso de ação preferível por um determinado sujeito (Achen; Snidal, 1989), a teoria da escolha racional ressoou na pesquisa criminológica (Akers, 1990) e nas políticas públicas de segurança e justiça criminal (Nagin; Pogarsky, 2001). A interpretação mais corrente ao longo dos anos 1990, época de maior expressão dessa teoria, era a de que, apesar de suas limitações, ela demonstrava como os recursos públicos poderiam ser mais bem aplicados na construção de uma sociedade sem crimes: a pedra angular do investimento público deveria ser o aumento do número de policiais, promotores e juízes e de vagas na prisão, sendo essa a melhor estratégia para a prevenção do delito.

Nos Estados Unidos da América, essa abordagem foi particularmente prolífica a partir de 1980, quando o diagnóstico sobre as causas do crime apontava, de forma quase uníssona, para a inexistência de profissionais e instituições encarregadas da repressão do delito (Akers, 1990). As teorias da dissuasão e da escolha racional foram utilizadas para aumentar massivamente a quantidade de recursos investidos no sistema de segurança pública e justiça criminal, bem como para justificar o encarceramento em massa (Akers; Sellers, 2004, p. 31). Os resultados desse modelo tardaram algumas décadas para aparecer, mas, já no início do século XXI, era visível como o aumento da quantidade de policiais e de funcionários do sistema de justiça tinha colaborado para o decréscimo das taxas de criminalidade, inclusive em cidades notoriamente violentas, como Nova Iorque, Chicago e Los Angeles (Zimring, 2011). Em algumas situações, os resultados gerados com esse excessivo investimento em agentes e agências de segurança pública e justiça criminal são questionáveis, dado que, mais do que a quantidade, o elemento determinante do efeito redução do crime seria a inteligência na aplicação desses recursos (Weisburd; Telep; Lawton, 2014).

Por isso, na perspectiva de Sanchez et al. (2003), é preciso resgatar a formulação original da teoria da dissuasão e testá-la de forma mais acurada com base nas informações sobre disponibilidade de recursos policiais e judiciais e sobre padrões de funcionamento deste sistema. Segundo os autores, somente de posse de tais dados, é possível construir uma espécie de equação que apresente a quantidade de crimes como o resultado da presença ou ausência de atores e agências do sistema de justiça criminal na localidade, independentemente do conhecimento de outras motivações dos indivíduos para a prática de delitos. Em certa medida, este é o exercício que se pretende realizar neste artigo.

\section{Os dados disponíveis no IMRS}

A análise de dados foi realizada em duas etapas. $\mathrm{Na}$ primeira parte, foram feitas análises descritivas demonstrando como a criminalidade violenta está distribuída no estado de Minas Gerais. Para isto se utilizaram registros policiais e, ainda, modelos de regressão linear, em que a quantidade de registros de crimes foi explicada com base nos elementos da teoria da dissuasão. A segunda parte da análise contou com a avaliação de modelos de regressão hierárquicos, em que foi possível investigar o impacto das variáveis apresentadas sobre as taxas de registro de crime violento, no período de 2006 a 2014.

Dois são os fenômenos que se pretende explicar: a taxa de registro de crimes violentos (delitos de homicídio, homicídio tentado, estupro, roubo e roubo àmão armada) e a taxa de homicídios dolosos, aqueles em que há a intenção de matar. A opção pela escolha de duas variáveis dependentes se deve à diferença existente entre quantidade de registros e quantidade 
de crimes, dado que um delito pode ocorrer sem ser devidamente transformado em um registro, um documento estatal que permita sua contabilização em bases de dados e sua posterior inclusão na análise. A diferença entre a quantidade de crimes ocorridos e a de crimes registrados é o que se denomina "cifra oculta da criminalidade" (Zackseski, 2000).

De acordo com Beato (2012), os crimes apresentam diferentes probabilidades de registros e, por conseguinte, de mensuração. O homicídio intencional tende a ser o delito com maior quantidade e qualidade de registros, por dois motivos: a existência do cadáver, que torna a prova de materialidade do crime imediata, e as múltiplas fontes de informação sobre o fenômeno, que tem registro no sistema de saúde e nas polícias. A existência dessas fontes contribui para a comparação e o controle dos dados da segurança pública. Ainda que haja alguma diferença entre a quantidade de mortes violentas intencionais computadas pela saúde e a quantidade contabilizada pela segurança pública, as curvas de tendência e as taxas tendem a ser muito semelhantes. O mesmo já não acontece com os demais delitos, já que seu registro depende da vontade do indivíduo e da confiança que ele deposita na polícia para tal.

Para Geélison Silva e Cláudio Beato (2013), o baixo grau de confiança nas polícias é um dos determinantes da reduzida probabilidade de o cidadão acionar a instituição quando vitimado por um crime. Quando esse funil entra em operação, as análises produzidas com base nos registros oficiais, apesar de procurarem estimar as chances de ocorrência do crime, acabam estimando, na verdade, as chances de registro. Para se ter uma ideia da magnitude do problema, comparando os percentuais de roubos ocorridos no país e apresentados pela Pesquisa Nacional de Vitimização ${ }^{4}$ com os percentuais reportados pelas organizações policiais, constata-se que tão somente $21 \%$ dos roubos ocorridos são comunicados às autoridades policiais. Neste caso, estamos falando de um delito cujo registro pode trazer benefícios ao indivíduo, como, por exemplo, o recebimento do seguro. Em delitos contra a pessoa, como lesão corporal e estupro, em que essa externalidade positiva não se faz presente, estima-se que menos de $10 \%$ das ocorrências são comunicadas à polícia.

Essa ressalva é importante porque, apesar de o propósito deste trabalho ser estimar a quantidade de delitos com base nas variáveis da teoria da dissuasão, no caso dos crimes violentos em geral, o que pode estar sendo apresentado é o tipo de variável que interfere na decisão de uma vítima de delito de registrar o evento em uma das duas polícias (militar ou civil). No caso dos homicídios dolosos, como a subnotificação é muito pequena e, por conseguinte, as taxas de registro são, em verdade, taxas de crime, é possível estimar a quantidade do delito. Logo, as duas modalidades permitem entender se existe diferença no efeito que a quantidade de recursos do sistema de segurança pública e justiça tem na quantidade de crimes registrados e na quantidade de homicídios dolosos, ao longo do período de dez anos, nas 853 cidades de Minas Gerais.

Estas cidades apresentaram crescimento da taxa de homicídios dolosos ao longo da série histórica analisada (2000-2014). Se, no início dos anos 2000, a taxa de homicídio intencional no estado tinha valor igual a 12,6 ocorrências por 100.000 habitantes, ${ }^{5} \mathrm{em}$ 2014 este valor era de 19,6 ocorrências por 100.000 habitantes, um aumento de quase $40 \%$ ao longo de quatorze anos. É interessante notar que, entre 2000 e 2007, a tendência da taxa era ascendente. Já entre 2007 e 2011, a taxa estava em declínio, mantendo-se, porém, em patamares elevados desde a virada da última década (Gráfico 1).

Gráfico 1 - Taxa de homicídio intencional - ocorrências por 100.000 habitantes, Minas Gerais (2000-2014)

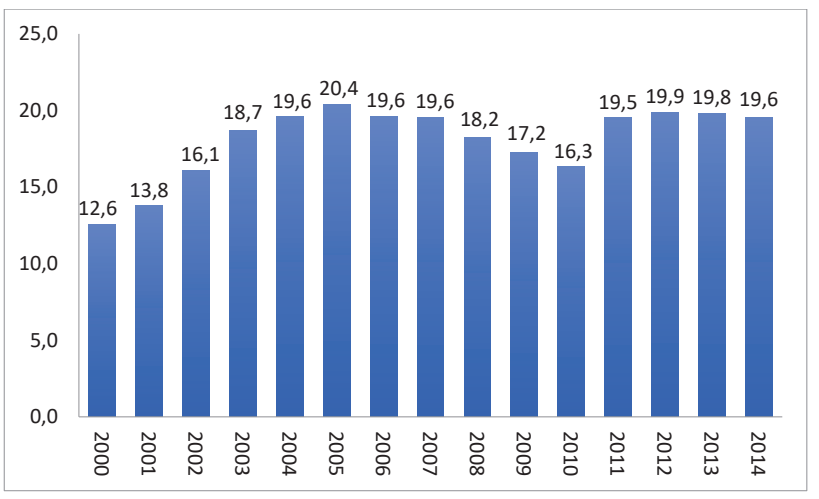

Fonte: IMRS

O segundo fator relevante para a análise é a constatação de que o crime não se distribui igualmente no território. A taxa de criminalidade tende a ser afetada pelo tamanho do município, ${ }^{6}$ sendo que algumas lo-

4. Dados disponíveis em http://www.crisp.ufmg.br/wp-content/uploads/2013/10/Relatório-PNV-Senasp_final.pdf e acessados em 7 de junho de 2016.

5. Esta informação é de extrema importância. Usualmente, as taxas de homicídios intencionais são calculadas com base na quantidade de vítimas, mas, no IMRS, elas são resultado da análise da quantidade de ocorrências, o que produz efeitos consideráveis sobre os números. Isso porque uma mesma ocorrência pode ter inúmeras vítimas (por exemplo, uma chacina em que vinte pessoas são mortas), no entanto, computase apenas uma ocorrência.

6. A maioria das cidades mineiras é de pequeno porte: dos 853 municípios, 477 têm até 10.000 habitantes, sendo que menos de $10 \%$ podem ser classificados como de grande porte (37 municípios tinham entre 50.000 e 100.000 habitantes, e somente 31 tinham acima de 100.000). 
calidades concentram uma quantidade muito maior de delitos do que outras. Beato (2012) argumenta que não existe uma explosão, e sim uma implosão da criminalidade, já que algumas cidades concentram quase todos os crimes registrados no estado.

Analisando a distribuição da taxa de registros de crimes violentos por 100.000 habitantes entre 2004 e 2014, é possível verificar que a zip law descrita por Beato (2012) se concentra nas cidades maiores, já que os bloxplots dos municípios com mais de 100.000 habitantes (apenas 31 das 853 cidades mineiras) possuem os valores mais elevados (Gráfico 2).

Gráfico 2 - Bloxplot das taxas de crimes violentos por 100.000 habitantes por porte dos municípios mineiros (2004-2014)

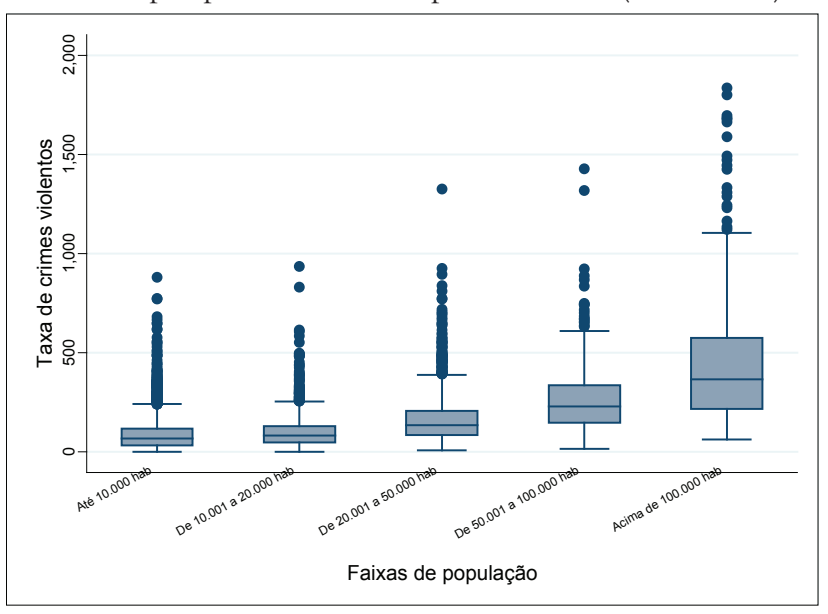

Fonte: IMRS

O bloxplot é o gráfico mais recomendável para a comparação de grupos diversos, segundo Silva e Adair $(2011$, p. 3), porque a caixa central representa $50 \%$ dos valores centrais, a linha central de cada caixa representa a mediana, e os extremos ou asteriscos mostram os valores máximos e mínimos de cada grupo. Logo, no período de 2004 a 2014, quanto maior o município, maior o intervalo de variação da distribuição da série e maior a mediana da taxa de registro de crimes violentos por 100.000 habitantes, o que indica maior concentração de crimes.

Dado o aumento considerável dos homicídios intencionais nos últimos dez anos no estado de Minas Gerais e a prevalência da criminalidade violenta nos municípios de grande porte, a proposta deste trabalho é entender como a disponibilidade dos aparatos e dos serviços de segurança pública e justiça criminal tem efeito nas taxas de crimes violentos em geral e nos homicídios dolosos em especial. Para tanto, foram utilizadas as informações disponíveis na esfera da segurança pública, que integram a base de dados do IMRS. O Quadro 1 procura detalhar o significado de cada uma das variáveis no contexto da teoria da dissuasão, bem como a forma de mensuração e, ainda, os anos para os quais a informação encontra-se disponível.

A primeira variável é a quantidade de habitantes por policial militar. A opção por essa variável refere-se à constatação de que a única agência relacionada à prestação de serviços de segurança pública que se faz presente em todos os 853 municípios, ao longo de toda a série histórica, é a polícia militar. As demais instituições se organizam de forma diferenciada, e por isso algumas cidades têm todos os tipos de organização ligada à justiça criminal (Delegacia de Polícia Civil, Promotoria de Justiça, Judiciário e Sistema Prisional), enquanto outras possuem apenas uma parte dessas agências. É de se esperar que cidades com todo o aparato institucional tenham maior probabilidade de registro, de apontamento de um suspeito (esclarecimento, processamento) e de punição dos delitos que nelas acontecem em comparação às cidades sem essas agências. Presume-se, portanto, que as taxas de crimes naquelas cidades serão menores ao longo do tempo.

Quadro 1 - Variáveis utilizadas na análise por abordagem, categoria mensurada e anos disponíveis na base de dados do IMRS

\begin{tabular}{|c|c|c|c|c|c|c|}
\hline \multirow[b]{2}{*}{ Abordagem } & \multirow[b]{2}{*}{ Estrutura } & \multicolumn{4}{|c|}{ Variável } & \multirow[b]{2}{*}{$\begin{array}{l}\text { Anos } \\
\text { disponíveis }\end{array}$} \\
\hline & & $\begin{array}{l}\text { Nome da } \\
\text { variável na } \\
\text { base de dados }\end{array}$ & $\begin{array}{l}\text { Significado } \\
\text { da variável }\end{array}$ & $\begin{array}{l}\text { Escala de } \\
\text { mensuração }\end{array}$ & $\begin{array}{l}\text { Definição } \\
\text { operacional }\end{array}$ & \\
\hline $\begin{array}{l}\text { Variáveis } \\
\text { independentes }\end{array}$ & $\begin{array}{l}\text { Patrulhamento } \\
\text { ostensivo } \\
\text { (prevenção) }\end{array}$ & P_PM & $\begin{array}{l}\text { Quantidade de } \\
\text { habitantes por } \\
\text { policial militar }\end{array}$ & $\begin{array}{l}\text { Contínua - } \\
\text { entre } 1 \text { e } 5.323\end{array}$ & $\begin{array}{l}\text { Razão entre a população total do } \\
\text { município e o número de policiais } \\
\text { militares lotados na unidade. O número } \\
\text { de policiais corresponde ao informado } \\
\text { pela corporação, que tem como } \\
\text { referência a data de } 31 \text { de dezembro } \\
\text { do ano em questão e computa apenas } \\
\text { os efetivos em serviço operacional da } \\
\text { polícia militar, nos quadros: oficial e } \\
\text { oficial-complementar (QOPM-QOC: } \\
\text { coronel, tenente-coronel, major, capitão, } \\
\text { tenente e aspirante) e praça (QPPM: } \\
\text { subtenente, sargento, cabo e soldado). }\end{array}$ & $2000-2014$ \\
\hline
\end{tabular}




\begin{tabular}{|c|c|c|c|c|c|c|}
\hline \multirow[b]{2}{*}{ Abordagem } & \multirow[b]{2}{*}{ Estrutura } & \multicolumn{4}{|c|}{ Variável } & \multirow[b]{2}{*}{$\begin{array}{l}\text { Anos } \\
\text { disponíveis }\end{array}$} \\
\hline & & $\begin{array}{l}\text { Nome da } \\
\text { variável na } \\
\text { base de dados }\end{array}$ & $\begin{array}{l}\text { Significado } \\
\text { da variável }\end{array}$ & $\begin{array}{l}\text { Escala de } \\
\text { mensuração }\end{array}$ & $\begin{array}{l}\text { Definição } \\
\text { operacional }\end{array}$ & \\
\hline \multirow{3}{*}{$\begin{array}{l}\text { Variáveis } \\
\text { independentes }\end{array}$} & $\begin{array}{l}\text { Capacidade de } \\
\text { esclarecimento } \\
\text { de delitos }\end{array}$ & Pdelegacia & $\begin{array}{l}\text { Existência de } \\
\text { delegacia da } \\
\text { polícia civil no } \\
\text { município } \\
\end{array}$ & $\begin{array}{l}0=\text { Não } \\
1=\text { Sim }\end{array}$ & $\begin{array}{l}\text { Existência de unidade vinculada à } \\
\text { polícia civil e que seja responsável pela } \\
\text { investigação de ilícitos penais. }\end{array}$ & $2000-2014$ \\
\hline & $\begin{array}{l}\text { Disponibilidade } \\
\text { de recursos } \\
\text { de repressão } \\
\text { imediata }\end{array}$ & Pcomarca & $\begin{array}{l}\text { O município é } \\
\text { sede da comarca }\end{array}$ & $\begin{array}{l}0=\text { Não } \\
1=\text { Sim }\end{array}$ & $\begin{array}{l}\text { Informa se o município é sede da } \\
\text { comarca, segundo dados do IBGE. }\end{array}$ & 2006-2014 \\
\hline & $\begin{array}{l}\text { Visibilidade } \\
\text { dos recursos de } \\
\text { repressão }\end{array}$ & Pepen & $\begin{array}{l}\text { O município tem } \\
\text { equipamento do } \\
\text { sistema prisional }\end{array}$ & $\begin{array}{l}0=\text { Não } \\
1=\text { Sim }\end{array}$ & $\begin{array}{l}\text { Indica se o município possui } \\
\text { estabelecimento penitenciário } \\
\text { (gerenciado pela Secretaria de Defesa } \\
\text { Social e destinado, prioritariamente, a } \\
\text { presos condenados) ou estabelecimento } \\
\text { prisional (gerenciado pela polícia civil } \\
\text { e destinado, prioritariamente, a presos } \\
\text { provisórios). }\end{array}$ & 2003-2014 \\
\hline \multirow[b]{2}{*}{$\begin{array}{l}\text { Variáveis } \\
\text { dependentes }\end{array}$} & $\begin{array}{l}\text { Violência contra } \\
\text { a pessoa }\end{array}$ & P_HOM_TX & $\begin{array}{l}\text { Taxa de } \\
\text { homicídios } \\
\text { intencionais }\end{array}$ & $\begin{array}{l}\text { Contínua - } \\
\text { entre } 0 \text { e } 98,7\end{array}$ & $\begin{array}{l}\text { Razão entre o número de ocorrências } \\
\text { de homicídio doloso (conforme a } \\
\text { caracterização determinada pelo } \\
\text { Código Penal Brasileiro) registradas } \\
\text { pelas polícias estaduais (militar e civil) e } \\
\text { a população do município multiplicada } \\
\text { por } 100.000 .\end{array}$ & $2000-2014$ \\
\hline & Criminalidade & P_CV & $\begin{array}{l}\text { Taxa de crimes } \\
\text { violentos }\end{array}$ & $\begin{array}{l}\text { Contínua } \\
\text {-entre } 0 \text { e } 1.696\end{array}$ & $\begin{array}{l}\text { Razão entre o número de ocorrências } \\
\text { de crimes violentos (homicídio, } \\
\text { homicídio tentado, estupro, roubo } \\
\text { e roubo à mão armada, conforme } \\
\text { a caracterização determinada pelo } \\
\text { Código Penal Brasileiro), registradas } \\
\text { pelas polícias estaduais (militar e civil) e } \\
\text { a população do município multiplicada } \\
\text { por } 100.000 .\end{array}$ & $2000-2014$ \\
\hline
\end{tabular}

Fonte: IMRS

Durante muito tempo, acreditou-se que a ONU estabelecia como número mágico 250 habitantes por policial (Wilson; Weiss, 2012). No entanto, o que existe, em verdade, é uma pesquisa da instituição para o cálculo da média de habitantes por policial. Segundo o último survey, realizado em 2010, a média mundial é de 400 policiais para cada 100.000 habitantes, ou seja, 250 habitantes por policial, aproximadamente. ${ }^{7}$ Em Minas Gerais, a média é de 934 habitantes por policial militar, um número bem acima do que se acreditava ser uma razão ideal estabelecida pelas Nações Unidas. Esse número é importante por dois motivos. Primeiro, porque a menor quantidade de habitantes por policial pode influenciar na dissuasão do sujeito motivado pela prática do delito: quando existem muitos policiais vigiando a ação dos cidadãos, é bem provável que qualquer infração seja prontamente identificada e registrada, o que aumenta a chance de ela ser processada e punida. Em segundo lugar, uma grande quantidade de policiais permite que a polícia militar seja acionada para providências relacionadas a um crime quando a vítima (ou outro indivíduo) decide comunicar esse delito a uma agência estatal.
No caso de comunicação de um delito, ao chegar ao local do crime, a polícia militar tentará prender o responsável pela infração ou recolher todas as provas que possam ajudar no apontamento do "criminoso" quando este não estiver mais presente. Cabe à instituição remeter todas as provas do crime e, se possível, o responsável por ele a uma delegacia de polícia. Porém, quando não há delegacia na localidade (o que ocorre em 70\% das cidades mineiras), cabe ao policial militar dirigir-se até uma delegacia de polícia, o que pode consumir horas a fio. Em sua ausência, outros crimes podem acontecer, e estes ficarão sem resposta, dada a falta de recursos humanos na localidade.

A polícia civil, por sua vez, deve reunir todas as provas relacionadas à autoria do delito e encaminhá-las para o Ministério Público, que tratará de iniciar o processo penal por meio de denúncia. Ocorre que, em Minas Gerais, a organização do Ministério Público e do Poder Judiciário se dá por comarcas, isto é, em um conjunto de cidades, apenas uma delas concentra essas organizações, tornando-se a sede da comarca. As sedes de comarca são responsáveis pelo 
processamento e julgamento de infrações que tenham lugar naquela circunscrição. São consideradas cidades-polo da região, pois nelas atuam o promotor, o juiz e o defensor. E como eles são responsáveis por dar atendimento adequado a todos os delitos ocorridos em todas as cidades que compõem a comarca, isto pode significar acúmulo de trabalho e prioridade para os casos que envolvam cidadãos das sedes, onde residem tais operadores.

Atualmente, apenas 35\% das cidades mineiras são sedes de comarca. Quando o delegado conclui suas investigações, reunidas em um expediente denominado inquérito policial, ele também deve dirigir-se até a sede de sua comarca, a fim de entregar toda essa documentação ao promotor de justiça. Em razão da distância entre as comarcas, esse percurso pode consumir várias horas. Ou seja, a cidade de atuação desse delegado ficará descoberta nesse intervalo, em que, mais uma vez, tem-se a probabilidade de ocorrência de crimes sem respostas.

Ao receber o inquérito policial, o promotor deve examinar os indícios reunidos pelo delegado de polícia e, caso existam indícios suficientes de que o delito ocorreu e de que o suspeito apontado é mesmo o responsável pelo crime, denunciar o sujeito, acusando-o publicamente. É a partir do aceite desta denúncia pelo juiz que se inicia o processo penal, através do qual se poderá responsabilizar e, se for o caso, punir o delinquente.

Uma vez iniciado o processo penal, se o suspeito e a vítima residem em outras cidades que não a sede da comarca, novamente, problemas de coordenação se tornam prováveis. Para a presença de tais indivíduos nas audiências de instrução e julgamento (AIJ), isto é, nos momentos em que o juiz ouve as versões de como o crime foi praticado e decide o destino do acusado, é necessário que tais envolvidos se desloquem por alguns quilômetros. $\mathrm{E}$ isto nem sempre é tarefa fácil quando o acusado não está preso, pois, neste caso, ele é quem deverá arcar com tais despesas. Se tudo correu bem e o processo penal pôde chegar ao final com uma sentença condenatória, este indivíduo deve ser encaminhado para uma unidade prisional. Os deslocamentos envolvidos nesta fase são menores, dado que aproximadamente $32 \%$ dos municípios mineiros possuem algum tipo de unidade prisional, sendo que, geralmente, estas unidades se concentram nas cidades que são sedes das comarcas.

Uma vez descrito o funcionamento do sistema de segurança pública e justiça criminal em Minas Gerais, passamos ao teste de nossas hipóteses de pesquisa.

\section{Análise de dados}

No intuito de desvelar como a disponibilidade de recursos de segurança pública e justiça criminal pode ter efeitos nas taxas de crimes violentos em geral e de homicídios dolosos em especial, foram estimados dois modelos de regressão linear multivariada. Um modelo é, em verdade, uma aproximação da realidade, que, no caso em tela, pode ser conseguida por meio de uma equação matemática representada da seguinte forma:

Modelo 1:taxa de registro de $\mathrm{CV}=\alpha+\mathrm{aX}+\mathrm{bZ}+\mathrm{cK}+\mathrm{dW}$

Modelo 2:taxa de registro de $\mathrm{HD}=\alpha+\mathrm{aX}+\mathrm{bZ}+\mathrm{cK}+\mathrm{dW}$ em que

$\mathrm{CV}=$ crimes violentos e

$\mathrm{HD}=$ homicídios dolosos.

As taxas de crimes violentos e de homicídios dolosos são as categorias que se pretende explicar com base nas variáveis independentes, relacionadas à disponibilidade de recursos e equipamentos de segurança pública e justiça criminal. Para tanto, optou-se pela regressão linear, já que as variáveis "respostas" apresentam uma escala de mensuração contínua e uma distribuição semelhante a uma curva normal. As categorias que são usadas como base da explicação, inscritas na equação com letras maiúsculas, são denominadas variáveis independentes.

O primeiro modelo estimado tem uma delimitação temporal muito específica, posto que diz respeito tão somente ao ano de 2014. Trata-se de uma tentativa de compreender se a teoria da dissuasão produz efeitos nos dias atuais. Este modelo apresentou um $\mathrm{R}^{2}$ ajustado de 0,199, o que significa dizer que a disponibilidade de recursos do sistema de justiça criminal nas localidades observadas consegue explicar, em média, $19,9 \%$ da variação da taxa de crimes violentos nos municípios de Minas Gerais no ano de 2014 (Tabela 1).

A quantidade de habitantes por policiais militares e o fato de o município ser sede de comarca não foram estatisticamente significantes. Porém, quanto maior a disponibilidade de recursos do sistema prisional e da polícia civil na localidade, maior a quantidade de crimes violentos registrados, com destaque para o efeito que as delegacias de polícia têm neste resultado: elas aumentam em 36,1 pontos a média de registros. Este fato indica que a disponibilidade deste equipamento leva os indivíduos que foram vítimas de crimes violentos a uma maior disposição para a publicização do evento, ou seja, para dar conhecimento às autoridades de sua vitimização. 
$\mathrm{O}$ segundo modelo estimado apresentou um $\mathrm{R}^{2}$ ajustado de 0,018, ou seja, a disponibilidade de recursos do sistema de justiça criminal nas localidades monitoradas consegue explicar, em média, $1,8 \%$ da variação da taxa de homicídios intencionais registrados no município no ano de 2014 (Tabela 2). Esse resultado demonstra que, com as mesmas variáveis, explica-se menos sobre a dinâmica dos homicídios dolosos do que sobre a dinâmica de registro dos crimes violentos.

Neste segundo caso, só as delegacias de polícia foram estatisticamente significativas, aumentando as chances de ocorrência do evento. Porém, seu efeito é bastante reduzido se comparado com os resultados do modelo anterior: a disponibilidade deste aparato da polícia civil aumenta somente em 0,09 pontos a média da taxa de homicídio doloso. Em parte, este resultado pode ser explicado pela função que a presença do cadáver assume na dinâmica de registro deste crime: é a prova material que vai contribuir para a publicização do evento, e não a presença do equipamento estatal. Logo, o que este resultado parece indicar é que, mesmo no caso dos homicídios intencionais, os equipamentos de segurança pública explicam a dinâmica de registro e não a dinâmica de ocorrência, ao contrário do explicitado na seção anterior.

O grande problema desses resultados é que eles não levam em conta a passagem do tempo nem o porte do município. Como destacado anteriormente, os modelos foram estimados considerando tão somente as taxas de criminalidade e os recursos institucionais disponíveis em 2014 nos municípios mineiros. No entanto, é preciso lembrar que os recursos são variáveis ao longo do tempo e que cidades maiores tendem a concentrar uma maior quantidade de crimes e aparatos em comparação com cidades menores. Por isso, é necessário controlar o efeito do ano e do porte do município.

Existem duas formas de controlar o efeito dessas categorias. A primeira é inserindo o tempo como uma variável contínua no modelo de regressão. No caso da taxa de crimes violentos, o $\mathrm{R}^{2}$ ajustado caiu para 0,099 com a adoção dessa estratégia, mas todas as variáveis independentes se tornaram estatisticamente significativas, com exceção do tempo. Aparentemente, com o passar dos anos, a maior disponibilidade de recursos institucionais contribuiu para um aumento nas taxas de registro de crimes, e não necessariamente da criminalidade. Essa hipótese parece se tornar mais clara quando o modelo de taxas de homicídio doloso é estimado com a inserção do tempo como uma variável contínua. O seu $\mathrm{R}^{2}$ ajustado cai para 0,03 e, neste caso, a única variável com significância estatística é a presença de unidade do sistema prisional, que aumenta a chance de ocorrência do evento, apontando em uma direção contrária à esperada pela teoria da dissuasão.

Tabela 1 - Resultados do modelo de regressão linear múltipla, ${ }^{\star}$ que estima a taxa de registro de crimes violentos por 100.000 habitantes em 2014, com base na disponibilidade de recursos de segurança pública e justiça criminal no município monitorado

\begin{tabular}{|l|c|c|c|c|}
\hline & $\begin{array}{c}\text { Coeficiente não } \\
\text { padronizado }\end{array}$ & Erro padrão & $\begin{array}{c}\text { Coeficiente } \\
\text { padronizado }\end{array}$ & Significância \\
\hline P_PM - Habitantes por policial militar & $-0,001$ & 0,012 & $-0,002$ & 0,958 \\
\hline Pdelegacia - Existência de delegacia civil & 238,831 & 23,170 & 0,361 & 0,000 \\
\hline Pcomarca - O município é sede da comarca & 4,550 & 19,203 & 0,012 & 0,813 \\
\hline Pepen - Existência de unidade prisional & 54,570 & 21,147 & 0,140 & 0,010 \\
\hline Constante & 115,698 & 13,256 & - & 0,000 \\
\hline
\end{tabular}

*Variável dependente: P_CV - Taxa de crimes violentos.

Fonte: IMRS.

Tabela 2 - Resultados do modelo de regressão linear múltipla, ${ }^{\star}$ que estima a taxa de registro de homicídios intencionais por 100.000 habitantes em 2014, com base na disponibilidade de recursos de segurança pública e justiça criminal no município monitorado

\begin{tabular}{|l|c|c|c|c|}
\hline & $\begin{array}{c}\text { Coeficiente não } \\
\text { padronizado }\end{array}$ & Erro padrão & $\begin{array}{c}\text { Coeficiente } \\
\text { padronizado }\end{array}$ & Significância \\
\hline P_PM - Habitantes por policial militar & 0,001 & 0,001 & 0,032 & 0,359 \\
\hline Pdelegacia - Existência de delegacia civil & 5,448 & 2,256 & 0,094 & 0,016 \\
\hline Pcomarca - O município é sede da comarca & $-1,034$ & 1,870 & $-0,032$ & 0,580 \\
\hline Pepen - Existência de unidade prisional & 3,833 & 2,059 & 0,112 & 0,063 \\
\hline Constante & 10,569 & 1,291 & - & 0,000 \\
\hline
\end{tabular}

^Variável dependente: P_HOM_TX - Taxa de ocorrências de homicídios dolosos (instituições de segurança pública)

Fonte: IMRS 
Ocorre que o modelo de regressão linear não é o mais apropriado para essa análise, já que, em um ano específico, os recursos podem ter aumentado substantivamente, enquanto em outro eles podem ter reduzido. Além disso, os recursos institucionais não são constantes no tempo, de maneira que a sua distribuição não é aleatória, mas sim impactada pelo fator "ano". Por isso, é importante controlar o modelo pela passagem do tempo para calcular erros padrões e intervalos de confiança mais robustos.

Um caminho para se controlar este efeito-ano é a construção de modelos hierárquicos, que permitem analisar os dados coletivamente quando as informações estão aninhadas em grupos. No caso deste estudo, as informações de todos os municípios de Minas Gerais estão agrupadas por anos. A utilização do modelo hierárquico é apenas para o controle das informações ao longo do tempo, então a única variável incluída no segundo nível é o ano (Figura 1). Nos dois modelos estimados neste trabalho, as informações sobre os municípios mineiros estarão agrupadas pela variável "ano". Procedendo desse modo, foi possível formar sete grupos (de 2006 a 2011 e em 2014), por conta da disponibilidade de informações para cada ano.

Figura 1 - Representação da estrutura hierárquica utilizada para a análise dos dados

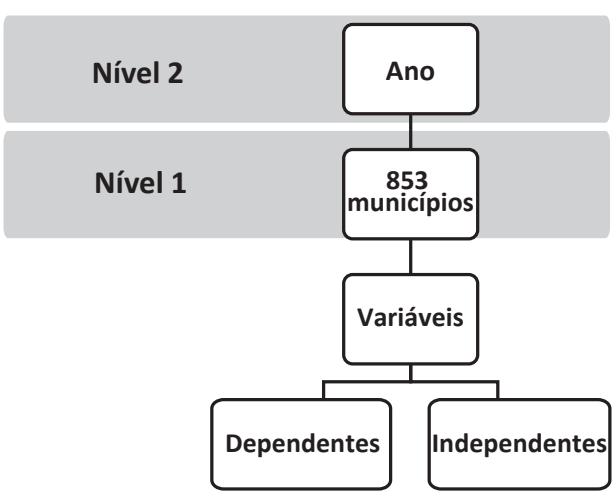

Fonte: Adaptado de Natis (2001)

No que se refere ao controle do efeito do porte dos municípios, este também é utilizado no mode- lo hierárquico, observando-se o número de habitantes por município. Como a maioria dos municípios de Minas Gerais é de pequeno porte, isto é, tem até 10.000 habitantes, foi criada uma variável dummy com valores 0 e 1 , que indicam municípios com mais de 10.000 habitantes e municípios com até 10.000 habitantes, respectivamente. O objetivo é controlar o efeito do porte do município nas taxas de crimes, como argumenta Beato (2012).

No primeiro modelo ajustado, que estima a taxa de crimes violentos, todas as variáveis foram significativas (Tabela 3). A variação desta taxa é explicada em 5,1\% pela variação entre os anos (Rho: 0,051). Além da significância das variáveis, vale destacar seus efeitos, ou seja, o que influencia no decréscimo da taxa de registro de crimes violentos é o número de habitantes por policial militar e o fato de o município ser sede da comarca. Em outras palavras, quanto maior a quantidade de habitantes que um único policial militar deve vigiar, menor a taxa de registro de crimes violentos. Isto pode indicar que, quando o crime acontece, o policial não está disponível e, por isso, ele não é registrado, o que aumenta a cifra oculta da criminalidade. Quanto ao fato de um município ser sede da comarca, isto significa que todos os recursos institucionais para processamento e punição de crimes estão disponíveis no local, sendo maior a probabilidade de dissuasão do comportamento criminoso. Esse fator poderia contribuir para a redução da taxa de crimes violentos (e não de seu registro).

Em relação à taxa de registro de homicídios intencionais por 100.000 habitantes (Tabela 4), pouco de sua variação é explicada pelos anos (Rho: 0,0003). No entanto, quando essa taxa é controlada pelo tempo, as variáveis "habitantes por policial militar" e "se o município é sede da comarca" possuem significância, ao passo que a variável "se o município possui delegacia" deixa de ser significativa. Outro fator que merece destaque é o efeito negativo da covariável "habitantes por policial militar", indicando que o aumento no número de habitantes por policial está

Tabela 3 - Resultados do modelo de regressão hierárquico linear,` que estima a taxa de registro de crimes violentos por 100.000 habitantes, com base na disponibilidade de recursos de segurança pública e justiça criminal no município monitorado

\begin{tabular}{|c|c|c|c|}
\hline & Coeficiente & Erro padrão & Significância \\
\hline P_PM - Habitantes por policial militar & $-0,033$ & 0,003 & 0,000 \\
\hline Pdelegacia - Existência de delegacia civil & 29,349 & 4,073 & 0,000 \\
\hline Pcomarca - O município é sede da comarca & $-20,785$ & 7,671 & 0,007 \\
\hline Pepen - Existência de unidade prisional & 28,918 & 7,766 & 0,000 \\
\hline POP10 - Municípios com até 10.000 habitantes & $-63,933$ & 4,759 & 0,000 \\
\hline Rho & 0,051 & 0,027 & - \\
\hline
\end{tabular}

*Variável dependente: P_CV - Taxa de crimes violentos.

Fonte: IMRS. 
correlacionado com uma menor taxa de homicídios. Outras variáveis significativas foram: se o município é sede da comarca e se possui até 10.000 habitantes.
Ambas parecem atuar de forma dissuasória, posto que reduzem a taxa de homicídios intencionais.

Tabela 4 - Resultados do modelo de regressão hierárquica linear,` que estima a taxa de registro de homicídios intencionais por 100.000 habitantes, com base na disponibilidade de recursos de segurança pública e justiça criminal no município monitorado

\begin{tabular}{|l|c|c|c|}
\hline & Coeficiente & Erro padrão & Significância \\
\hline P_PM - Habitantes por policial militar & $-0,001$ & 0,000 & 0,027 \\
\hline Pdelegacia - Existência de delegacia civil & $-0,029$ & 0,445 & 0,948 \\
\hline Pcomarca - O município é sede da comarca & $-4,631$ & 0,997 & 0,000 \\
\hline Pepen - Existência de unidade prisional & 1,343 & 1,011 & 0,184 \\
\hline POP10 - Municípios com até 10.000 habitantes & $-5,630$ & 0,614 & 0,000 \\
\hline Rho & 0,0003 & - & - \\
\hline
\end{tabular}

*Variável dependente: : P_HOM_TX - Taxa de ocorrências de homicídios dolosos (instituições de segurança pública).

Fonte: IMRS.

Como no caso dos crimes violentos, o modelo parece ajudar na compreensão tanto da dinâmica de registro quanto da dinâmica de ocorrência do homicídio doloso. Por isso, é preciso prestar mais atenção aos resultados do modelo quando ele procura explicar a magnitude das taxas desse delito. Neste caso, os resultados tanto reforçam quanto rechaçam pressupostos da teoria da dissuasão, sendo esse o tema da próxima seção.

\section{O que dizem os dados?}

O objetivo deste trabalho é testar o efeito da disponibilidade dos recursos institucionais nos registros de crimes violentos e nas taxas de homicídios dolosos. Os resultados encontrados apresentaram aspectos difusos.

Primeiramente, a análise da presença de recursos institucionais não apresenta resultados semelhantes para crimes diferentes. Os resultados encontrados no modelo estimado para a taxa de homicídios dolosos diferem muito dos relacionados aos registros de crimes violentos.

A quantidade de habitantes por policial no município parece não estar correlacionada com a ocorrência de homicídios, dado que, apesar de significativa, a variável apresenta um efeito muito pequeno. Já o fato de um município ser sede da comarca diminui as chances de ocorrência do homicídio intencional, provavelmente porque isso significa maior facilidade de processamento e punição dos responsáveis. Por fim, o fato de os municípios terem menos de 10.000 habitantes também possui correlação negativa com a quantidade de mortes violentas intencionais, o que pode ser explicado pela "eficácia coletiva"» presente nessas cidades e ausente nas relações impessoais das grandes metrópoles, como argumentam Bráulio Silva e Cláudio Beato (2013). Esses resultados levam à hipótese de que o aparato institucional influencia na dinâmica dos homicídios, ainda que, dado o baixo poder explicativo do modelo e a importância do tamanho das cidades, tal influência seja reduzida.

Já em relação às taxas de crimes violentos, os aparatos institucionais avaliados estão relacionados com a variação desses números. No entanto, não foram todas as correlações que apresentaram valores negativos, ou seja, a presença desses aparatos pode não significar diminuição das taxas. A existência de delegacia civil e de unidade prisional está associada ao aumento da ocorrência de crimes violentos. Apesar dos resultados dos modelos estimados, não se pode concluir que a presença das instituições estatais está ocasionando maior cometimento de crime. Duas hipóteses podem ser usadas para avaliar esses resultados.

A primeira diz respeito à questão do registro dos crimes. A presença de delegacia civil no município pode facilitar o registro desses crimes, criando uma discrepância de números, mas não um aumento de eventos. A conclusão é a relação positiva entre essas duas variáveis: mais agências e agentes de segurança pública significa maior probabilidade de o cidadão comunicar a vitimização por crime violento, diminuindo a cifra oculta da criminalidade. A segunda refere-se à existência de unidade prisional no município.

8. De acordo com os autores, a eficácia coletiva ocorre em localidades urbanas e pode ser entendida como o resultado de comportamentos de determinados residentes que ajudam a inibir a ocorrência de violência, especialmente, a interpessoal pessoal, independente da composição demográfica da população residente na área. 
Apesar de tais unidades serem indicadores de aparato estatal para a punição, sua presença também é vista como um fator que pode aumentar a criminalidade, em razão da inserção de uma nova dinâmica de sociabilidade na localidade. Nessa perspectiva, um maior aprisionamento acarreta desordem social, desigualdade e desestruturação nas famílias, fatores relacionados com o aumento da criminalidade (Clear, 1996). Assim, os resultados sobre a existência de unidade prisional vão contra o referencial teórico que pauta este trabalho, mas não são inconsistentes.

Por fim, a variável "habitantes por policial militar" apresentou um resultado não esperado pelo estudo. De acordo com os modelos econométricos, a maior quantidade de habitantes por policial militar significa menores taxas tanto de crimes violentos quanto de homicídios dolosos. Segundo os referenciais teóricos aqui adotados, era de se esperar que a menor quantidade de habitantes por policial é que estivesse correlacionada com menores taxas. Contudo, a relação apresentada é inversa: quanto maior a quantidade de habitantes por policial, menor a quantidade de crimes. Ou seja, quando o efeito avaliado é controlado pelo porte do município, o maior aparato policial não consegue influenciar negativamente nem as taxas de registros de crimes violentos, nem as taxas de ocorrência de homicídios dolosos. Essa variável deveria ser analisada mais qualitativamente, a fim de se entender como os policiais militares atuam nos municípios.

Aparentemente, localidades com recursos escassos (maior quantidade de habitantes por policial) concentram seus recursos de maneira estratégica, o que pode, por um lado, contribuir para a redução dos homicídios intencionais (efeito dissuasão), mas, por outro, aumentar a possibilidade de não registro de crimes violentos, como o roubo, já que o policial não está disponível em todas as localidades. Em outros termos, diante da carência de recursos, os policiais são mais eficientes na missão de prevenção à morte violenta, de sorte que este "fazer mais com menos" poderia ser uma explicação para a queda da criminalidade, como observado no caso de Nova Iorque por Weisburd, Telep e Lawton (2014). No entanto, não se pode esquecer que o diminuto efetivo policial é uma das variáveis que interfere na elevada cifra oculta da criminalidade, como apontado por Beato (2012).

\section{Considerações finais}

A proposta deste trabalho foi resgatar uma das primeiras teorias sociológicas sobre determinantes do comportamento criminoso, a teoria da dissuasão. Formulada ainda no século XVIII, sob a égide das ideias de Bentham e de Beccaria, essa teoria enten- de que o comportamento criminoso é decorrente de um cálculo racional em que o indivíduo avalia se o sistema de justiça criminal é eficiente o bastante para detectar e processar um fato criminoso. Caso a resposta seja negativa, as motivações para o crime já se encontram como dadas. Ao final da década de 1960, essa abordagem foi resgatada com uma roupagem estritamente econômica, sendo denominada de teoria da escolha racional.

A teoria da escolha racional é baseada na ideia de retornos marginais da conduta criminal, tendo sido desenvolvida por distintos economistas a partir da década de 1970. Seu autor de maior destaque é Gary Becker, cuja proposta era empreender um profundo cálculo econométrico dos determinantes do comportamento criminoso. Por meio desse cálculo, esperava-se que o Estado de bem-estar social pudesse otimizar seus recursos investidos na prevenção de delitos, centrando-se efetivamente nos elementos que fossem capazes de conter a atividade criminosa. O principal desdobramento dessa teoria, do ponto de vista da intervenção estatal, foi o aumento na quantidade de agentes e agências do sistema de justiça criminal como forma de prevenção de delitos (Akers; Sellers, 2004). Em algumas cidades norte-americanas, tal desdobramento teria sido determinante para a queda das taxas de crimes violentos em geral e de homicídios dolosos em especial (Zimbring, 2011).

Todavia, os estudos sobre efeitos do encarceramento em massa indicam que as penas mais longas não tiveram o potencial de redução da criminalidade, o que deu ensejo ao questionamento da eficácia da teoria da escolha racional na explicação da redução da criminalidade (Akers; Sellers, 2004). Além disso, muito se argumenta sobre a importância de uma aplicação parcimoniosa dos recursos humanos no espaço, de forma a inibir a seletividade e, desse modo, aumentar a efetividade da prevenção (Weisburd; Telep; Lawton, 2014).

No caso dos municípios de Minas Gerais, os efeitos do investimento em agentes e agências do sistema de segurança pública e justiça criminal como forma de redução da criminalidade foram relativamente distintos dos esperados. A maior disponibilidade de policiais não contribui nem para a redução dos homicídios, nem para a redução dos crimes violentos nesses municípios. Neste caso, é preciso compreender como os policiais se distribuem no território, pois sua ausência em áreas de maior concentração da violência é o que pode estar concorrendo para esse resultado (Weisburd; Telep; Lawton, 2014). Nos Estados Unidos, a grande crítica feita aos desdobramentos da teoria da dissuasão é, inclusive, que ela pode ter contribuído para a redução da criminalidade, mas teve como efeito perverso um encarceramento extremamente seletivo, dado o foco 
dos policiais nos migrantes e afrodescendentes, que nem sempre são os responsáveis pelos delitos que acontecem no território (Akers; Sellers, 2004).

Os modelos de regressão, em certa medida, mostram que investir no aumento da quantidade de recursos humanos e institucionais de segurança pública e justiça criminal, por si só, não é suficiente para reduzir a criminalidade violenta, já que outros fenômenos parecem intervir na incidência desses delitos.

Nesse diapasão, uma última categoria que merece destaque é o tamanho do município. Cidades com menos de 10.000 habitantes têm taxas de crimes violentos e de homicídios dolosos substantivamente mais baixas do que cidades maiores, o que indica que a prevenção desses delitos estaria associada a uma forte estrutura de controle social informal, algo que é mais premente nas localidades pequenas do que nas grandes cidades (Silva; Beato, 2013). Nesse contexto, a criminalidade violenta seria resultado do enfraquecimento dos laços sociais e da falta de eficácia coletiva, categorias que, infelizmente, ainda não podem ser testadas por meio da base de dados do IMRS.

\section{Referências}

ACHEN, Christopher.; SNIDAL, Duncan. Rational deterrence theory and comparative case studies. World Politics, v. 41, n. 2, p. 143-169, 1989.

AKERS, Ronald. Rational choice, deterrence, and social learning theory in criminology: The path not taken. The Journal of Criminal Law and Criminology, v. 81, n. 3, p. 653676, 1990.

AKERS, Ronald; SELLERS, Christine. Criminological theories: introduction, evaluation and application. Oxford: Oxford University Press, 2004.

AZEVEDO, Rodrigo Ghiringhelli. A força do direito e a violência das formas jurídicas. Revista de Sociologia e Política, v. 19, n. 40, p. 27, 2011.

BEATO, Claudio. Crimes e cidades. Belo Horizonte: Editora UFMG, 2012.

BECCARIA, Cesare. Dos delitos e das penas. Tradução de Paulo M. Oliveira. Rio de Janeiro: Ediouro, 1965.

BECKER, Gary. Crime and punishment: An economic approach. Journal of Political Economy, n. 76, p. 169-217, 1968. BENTHAM, Jeremy. Panopticon or the inspection house. London: T. Payne, 1791.

BENTHAM, Jeremy. Teoria das penas legais e tratado dos sofismas políticos. São Paulo: Edijur, 2002.

CLEAR, Todd. Backfire: When incarceration increases crime. New York: Vera Institute of Justice, 1996. Paper presented at The unintended consequences of incarceration.

ELIAS, Norbert. O processo civilizador. Tradução de Ruy Jungmann. Rio de Janeiro: Zahar, 1993. v. 2 (Formação do Estado e Civilização).

FOUCAULT, Michel. A verdade e as formas jurídicas. Trad. Roberto Cabral de Melo Machado e Eduardo Jardim Morais. Rio de Janeiro: Nau, 2001.

FREITAS, Renan; RIBEIRO, Ludmila. Some current developments in Brazilian sociology of crime: Towards

a criminology? International Journal of Criminology and Sociology, v. 3, p. 175-185, 2014.

IGNATIEFF, Michael. State, civil society, and total institutions: A critique of recent social histories of punishment. Crime and Justice, v. 3, p. 153-192, 1981.
NAGIN, Daniel.; POGARSKY, Greg. Integrating celerity, impulsivity, and extralegal sanction threats into a model of general deterrence: Theory and evidence. Criminology, v. 39, n. 4, p. 865-892, 2001.

NATIS, Lilian. Modelos hierárquicos lineares. Estudos em Avaliação Educacional, n. 23, p. 3-29, 2001.

PIRES, Álvaro. A racionalidade penal moderna, o público e os direitos humanos. Novos Estudos Cebrap, v. 68, n. 3, p. 39-60, 2004.

SÁNCHEZ, Fabio; ESPINOSA, Silvia; RIVAS, Angela. Garrote o zanahoria? Factores asociados a la diminucion de la violencia homicida y el crimen en Bogotá, 1993-2002. Universidad de los Andes: CEDE, 2003.

SILVA, Geélison; BEATO, Cláudio. Confiança na polícia em Minas Gerais: o efeito da percepção de eficiência e do contato individual. Opinião Pública, v. 19, n. 1, p. 118-153, 2013.

SILVA, Janaina Gomes; ADAIR, Marcos Pereira Marinho. Atividade da enzima nitrato redutase em espécies arbóreas da Floresta Ombrófila Densa Submontana, Caraguatatuba, SP. In: REUNIÃO ANUAL DO INSTITUTO DE BOTÂNICA, 18., 2011. Anais... São Paulo, Raibt, 2011.

SILVA, Bráulio Figueiredo Alves da; BEATO, Claudio. Ecologia social do medo: avaliando a associação entre contexto de bairro e medo de crime. Revista Brasileira de Estudos Populacionais, v. 30, p. 155-170, 2013. Suplemento. SKOLNICK, Jerome Herbert; BAYLEY, David. Policiamento comunitário: questões e práticas através do mundo. Tradução de Ana Luiza Amêndola Pinheiro. São Paulo: Edusp, 2006. SKOLNICK, Jerome Herbert. Justice without trial. Chicago: University Press, 1966.

WEISBURD, David; TELEP, Cody; LAWTON, Brian. Could innovations in policing have contributed to the New York City crime drop even in a period of declining police strength? The case of stop, question and frisk as a hot spots policing strategy. Justice Quarterly, v. 31, n. 1, p. 129-153, 2014.

WILSON, Jeremy; WEISS, Alexander. A performancebased approach to police staffing and allocation. Washington: US Department of Justice Office of Community Oriented 
Policing Services, 2012.

ZACKSESKI, Cristina. Da prevenção penal à nova prevenção. Revista Brasileira de Ciências Criminais, n. 29, p. 167-191, 2000.
ZIMRING, Franklin. The city that became safe: New York's lessons for urban crime and its control. OUP USA: Chicago University Press, 2011.

\title{
What determines a crime occurrence and/ or registration in Minas Gerais?
}

\begin{abstract}
The purpose of this paper is to understand how crimes rates and their records are affected by the availability of resources and public security and criminal justice. As empirical counterpoint of this analysis it was used the "Índice Mineiro de Responsabilidade Social" (IMRS), which gathers data, aggregated at the city level, about health, education, housing and environment, public safety, income and employment, fiscal management, culture, sports and leisure, for the period of ten years (2004-2014). From the statistical modeling of the public security data available, it was found that the greater the human and institutional resources of public safety and criminal justice is, the greater the concentration of criminality records and crime itself, contrary to what presupposes the international criminological literature.
\end{abstract}

Keywords: Criminological theory, IMRS, violent crimes, murders.

\section{¿Qué determina la ocurrencia y/ o el registro de un crimen en Minas}

\section{Gerais?}

\section{Resumen}

La propuesta de este trabajo es comprender cómo las tasas de crimen y sus registros son afectados por la disponibilidad de recursos y servicios de seguridad ciudadana y justicia criminal. Como contrapunto empírico de este análisis, fue utilizado el Índice de Responsabilidad Social del estado de Minas Gerais (IMRS), que reúne datos, en el ámbito municipal, acerca de la salud, educación, vivienda y medio ambiente, seguridad ciudadana, renta y empleo, gestión fiscal, cultura, deporte y ocio, de un periodo de diez años (20042014). A partir de un tratamiento estadístico de los datos disponibles para el área de seguridad ciudadana, fue posible constatar que cuanto más grande era la disponibilidad de recursos humanos e institucionales de seguridad ciudadana y de justicia criminal, más grande la concentración de registros de criminalidad y de crimen (en sí mismo), al revés de lo que supone la literatura criminológica internacional.

Palabras clave: teoría criminológica, IMRS, crímenes violentos, homicidios intencionales.

Data de recebimento do artigo: $05 / 2016$

Data de aprovação do artigo: 11/2016 